\title{
Global radiative forcing from contrail cirrus
}

\author{
Ulrike Burkhardt` and Bernd Kärcher
}

\begin{abstract}
Aviation makes a significant contribution to anthropogenic climate forcing. The impacts arise from emissions of greenhouse gases, aerosols and nitrogen oxides, and from changes in cloudiness in the upper troposphere. An important but poorly understood component of this forcing is caused by 'contrail cirrus'-a type of cloud that consist of young line-shaped contrails and the older irregularly shaped contrails that arise from them. Here we use a global climate model that captures the whole life cycle of these man-made clouds to simulate their global coverage, as well as the changes in natural cloudiness that they induce. We show that the radiative forcing associated with contrail cirrus as a whole is about nine times larger than that from line-shaped contrails alone. We also find that contrail cirrus cause a significant decrease in natural cloudiness, which partly offsets their warming effect. Nevertheless, net radiative forcing due to contrail cirrus remains the largest single radiative-forcing component associated with aviation. Our findings regarding global radiative forcing by contrail cirrus will allow their effects to be included in studies assessing the impacts of aviation on climate and appropriate mitigation options.
\end{abstract}

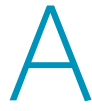
viation-induced cloudiness consists of contrail cirrus (of which a subset is line-shaped) and of changes in the occurrence or properties of natural cirrus arising from both the presence of contrail cirrus and increased ice-nuclei concentrations in the upper-troposphere due to aircraft soot emissions. Observations indicate that these changes may have a significant effect on cirrus cloudiness ${ }^{1}$. Radiative forcing-a measure of the radiative imbalance of the atmosphere caused by a particular forcing agent-due to aircraft-induced cloudiness has been estimated from observed trends in cirrus cloudiness to range approximately between 10 and $80 \mathrm{~mW} \mathrm{~m}^{-2}$ for the year 2005 (refs 2-4).

Contrail cirrus initially form behind cruising aircraft as lineshaped contrails and transform into cirrus-like clouds or cloud clusters in favourable meteorological conditions, occasionally covering large horizontal areas ${ }^{5-7}$. They have been tracked for up to $17 \mathrm{~h}$ in satellite observations ${ }^{6}$. They remain line-shaped, and therefore easily distinguishable from natural cirrus, for only a fraction of their lifetime. The impact of aircraft soot emissions on cirrus in the absence of contrails depends on the ice-nucleating properties and the ice-active number concentration of soot-particle emissions. Both of these parameters are highly uncertain ${ }^{8}$, and whereas the impact of aircraft soot on cirrus has been shown to be statistically significant in terms of cirrus ice-particle-number concentrations ${ }^{9}$ in a climate model, at present this can not be shown for radiative forcing ${ }^{10}$.

Contrail cirrus are composed of ice crystals that-similarly to natural cirrus_-reflect solar short-wave radiation and trap outgoing long-wave radiation ${ }^{11}$. For fixed ambient conditions, their radiative effect is mainly determined by their coverage and optical depth ${ }^{12}$. Contrail cirrus form and persist in air that is ice-saturated ${ }^{13,14}$, whereas natural cirrus often require high ice supersaturation to form ${ }^{15}$. This implies that in a substantial fraction of the upper troposphere, contrail cirrus can persist in supersaturated air that is cloud-free ${ }^{16,17}$, thus increasing high cloud coverage ${ }^{1,11,18}$. Remotesensing studies have estimated line-shaped-contrail coverages as large as a few per cent in regions in which the levels of air traffic are high ${ }^{19-21}$. The coverage due to contrail cirrus is as yet unknown because they are difficult to distinguish from natural cirrus in satellite observations ${ }^{11}$.

The global radiative forcing due to line-shaped contrails has been estimated to amount to $10 \mathrm{~mW} \mathrm{~m}^{-2}\left(6-15 \mathrm{~mW} \mathrm{~m}^{-2}\right)$ for 2005 , with a low level of scientific understanding ${ }^{4}$. The global radiative-forcing estimates for line-shaped contrails ${ }^{22}$ rely on the scaling of simulated contrail-formation frequency to an observed regional contrail coverage. Assuming the scaling coefficient to be spatially and temporally constant, global contrail coverage can be inferred $^{16,23}$. This methodology is not suited to studying the effect of contrail cirrus ${ }^{24}$. Present studies have been unable to provide a best estimate for the contrail-cirrus radiative forcing.

We have developed a process-based contrail-cirrus module ${ }^{17,25}$ (CCMod) in a global climate model, ECHAM4 (ref. 26; see Methods), which enables the simulation of the life cycle of persistent contrails. Contrail cirrus exist alongside and interact with natural clouds and, depending on their overlap with natural clouds, can increase overall cloud coverage. Here, we use our contrailcirrus module to simulate contrail-cirrus coverage, the associated radiative forcing and resulting changes in the natural cirrus clouds.

\section{Contrail-cirrus coverage}

Coverage due to contrail cirrus and that due to young contrails (defined here as up to $5 \mathrm{~h}$ old) are shown in Fig. 1. Coverage due to young contrails may be compared to the coverage inferred from satellite observations, because young contrails are most likely to be still line-shaped. Using a maximum random overlap scheme, contrail-cirrus coverage (Fig. 1a) amounts to several per cent over large parts of the Northern Hemisphere. Coverage due to persistent young contrails reaches $2 \%$ over Europe and exceeds $1 \%$ over large parts of the US (Fig. 1b), which is in line with earlier estimates of line-shaped-contrail coverage obtained by an independent technique ${ }^{22}$. Over central Europe, contrail-cirrus coverage is largest, reaching up to $10 \%$. Although the level of air traffic over the east coast of northern America is as large as over central Europe, contrail-cirrus coverage in the former region is lower, reaching $6 \%$. It is mainly the coverage due to contrails older than $5 \mathrm{~h}$ that is smaller over the USA than over Europe (see 


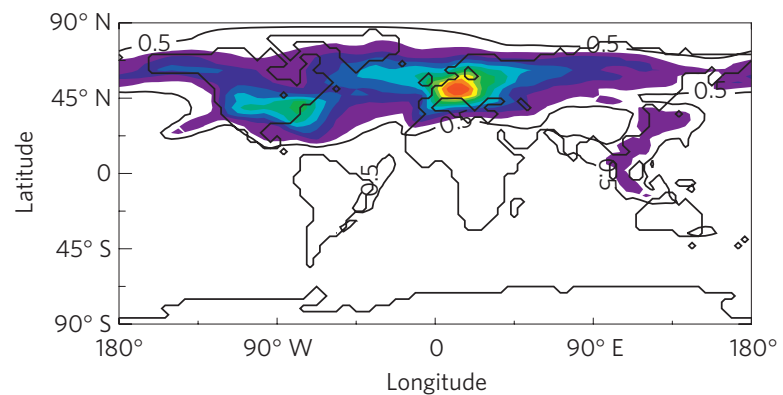

b
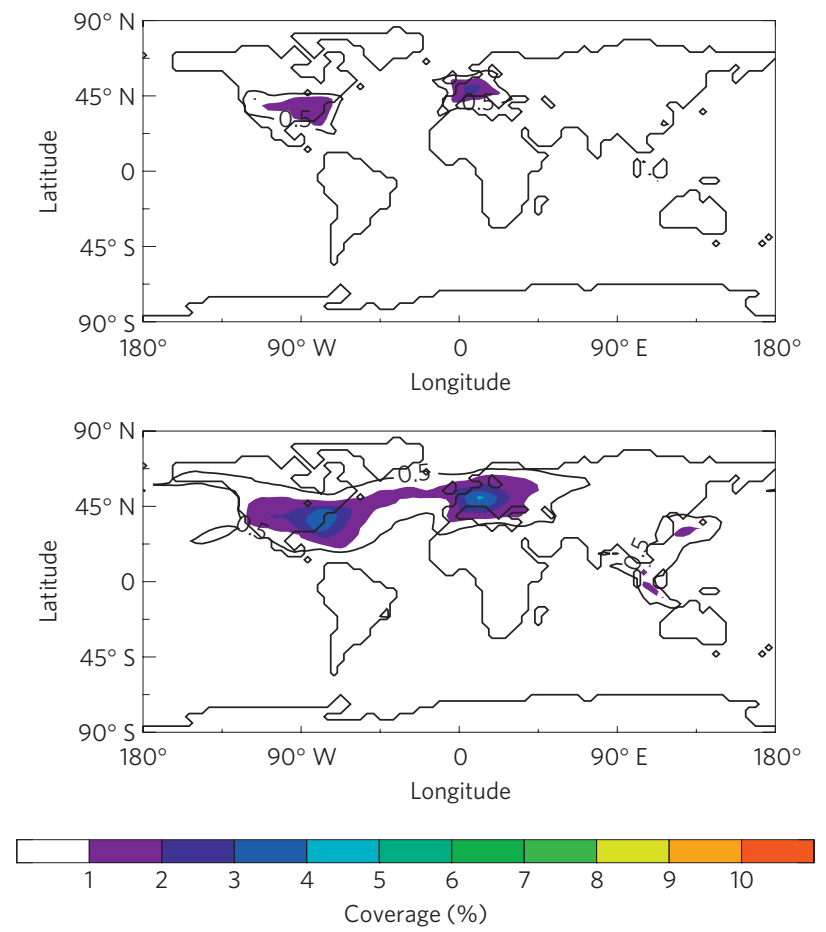

Figure 1 | Contrail-cirrus and young-contrail coverage for the year 2002 as simulated by ECHAM4-CCMod. a,b, Coverage due to contrail cirrus (a) and due to persistent young contrails with ages of up to $5 \mathrm{~h} \mathrm{(b)}$, considering young contrails and contrail cirrus of any optical depth. $\mathbf{c}$, Coverage due to visible contrail cirrus with a solar optical depth $>0.02$. Coverages have been calculated by assuming maximum random overlap among contrails or contrail cirrus alone. Only part of the contrail/contrail-cirrus coverage leads to an increase in overall cloud coverage.

below). This is mainly caused by the fact that many old contrails are advected into central Europe from the North Atlantic flight corridor, an area favourable to contrail formation and persistence, whereas there is little contrail advection towards the eastern part of the US. Furthermore, warmer temperatures over the US reduce the probability of contrail formation so that coverage due to young contrails is also slightly smaller than over central Europe. Over the east coast of southeast Asia, the area in which air traffic density is third largest, young-contrail coverage reaches $0.2 \%$ and contrailcirrus coverage exceeds $1 \%$. Globally averaged contrail-cirrus and young-contrail coverage amount to $0.61 \%$ and $0.07 \%$, respectively. Contrail-cirrus coverage is therefore approximately nine times larger than coverage due to young contrails alone.

Contrail-cirrus coverage (Fig. 1a) exceeds the coverage due to young contrails (Fig. 1b) significantly. The fraction of the total contrail-cirrus coverage that is due to young contrails (Fig. 2) amounts to 0.11 globally and is spatially very variable. In the area of the North Atlantic flight corridor only a small fraction (0.1-0.15) of the contrail-cirrus coverage is due to young contrails. The fraction

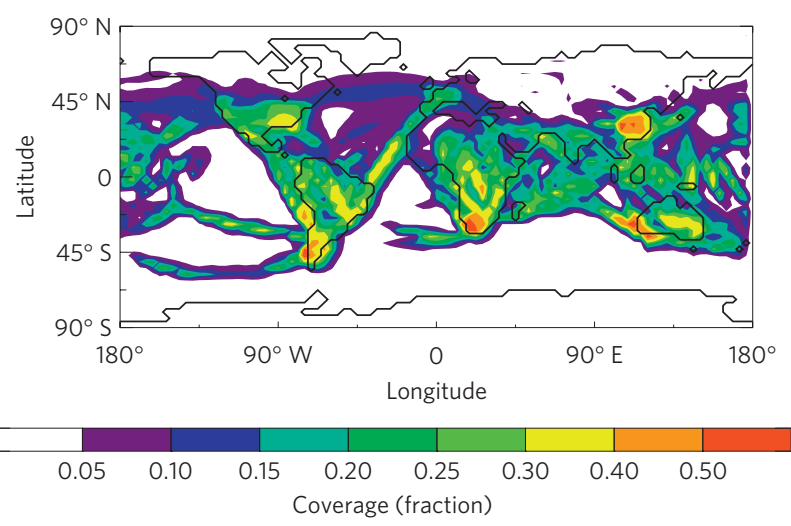

Figure 2 | Fraction of contrail-cirrus coverage that is identified as coverage due to young (age $\leq 5 \mathrm{~h}$ ) contrails.

of young contrails from the contrail-cirrus coverage lies between 0.15 and 0.25 over central Europe and between 0.25 and 0.4 over the eastern US. Over southeast Asia, a large part of contrail-cirrus coverage is due to young contrails.

A large fraction of contrail cirrus is optically very thin (solar optical depth $<0.02$ ) and can therefore neither be detected by a satellite nor seen with the human eye from the ground ${ }^{27}$. Owing to their abundance, the radiative effect of such optically thin contrail cirrus may not be negligible ${ }^{28}$, similar to the effect of optically thin natural cirrus ${ }^{29}$. The fraction of optically thin contrail cirrus is larger in colder areas (farther north), where ice-supersaturation frequency, at the main flight level $(230 \mathrm{hPa})$, is usually larger and the water content of the air is lower. This means that the contrailformation criterion is more frequently met, but contrails forming and persisting in those areas are less likely to become optically thick. Therefore, the fraction of optically thin contrail cirrus is larger over Europe than over the US and especially over southeast Asia. When considering only contrail cirrus that exceed a threshold optical depth of 0.02 , the coverage due to these visible contrail cirrus is fairly similar over the eastern US and central Europe and amounts to above $3 \%$ and up to $4 \%$, respectively (Fig. 1c). Over southeast Asia, most contrail cirrus are visible because of the higher specific water content, and coverage due to visible contrail cirrus amounts to $0.5 \%$, exceeding locally $1 \%$. Coverage due to visible young contrails reaches $1 \%$ over the southeast US and over central Europe and exceeds $0.2 \%$ over southeast $\mathrm{Asia}^{25}$. Globally, coverage due to visible contrail cirrus amounts to $0.23 \%$, whereas coverage associated with visible young contrails amounts to $0.04 \%$.

\section{Contrail-cirrus optical depth and radiative forcing}

Stratosphere-adjusted radiative forcing due to both young contrails and contrail cirrus was calculated online within the climate model (see Methods). The former estimate serves solely for comparison with previous results. As CCMod does not allow the calculation of the optical depth of young contrails alone, we assume that the optical depth of young contrails (averaging over $5 \mathrm{~h}$ ) is equal to that of contrail cirrus (averaging over all ages). There are no data available to estimate the difference in optical depth between young contrails and contrail cirrus, but we conjecture that this assumption is likely to lead to an underestimation of young-contrail optical depth and the associated net radiative forcing.

Globally, the long-wave radiative forcing due to contrail cirrus (after correcting the scattering component of the long-wave forcing from the model $^{30}$ ) amounts to $47.1 \mathrm{~mW} \mathrm{~m}^{-2}$ and short-wave radiative forcing to $-9.6 \mathrm{~mW} \mathrm{~m}^{-2}$, resulting in a net radiative forcing of $37.5 \mathrm{~mW} \mathrm{~m}^{-2}$. This includes the effect of line-shaped contrails. Globally averaged contrail-cirrus optical depth is 0.05 . Net radiative forcing of contrail cirrus (Fig. 3a) reaches values larger 
a
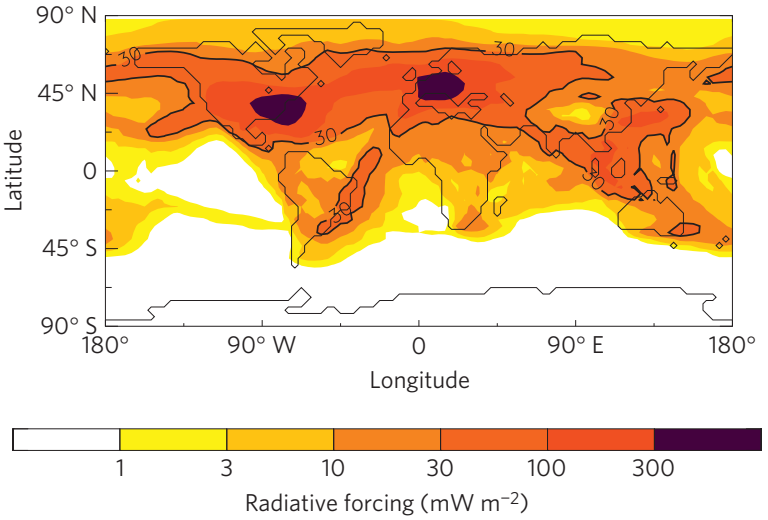

b

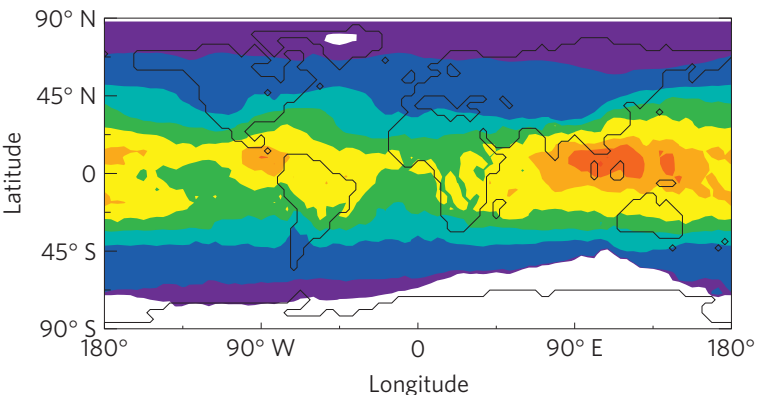

$\begin{array}{lllllll}0.005 & 0.010 & 0.030 & 0.050 & 0.070 & 0.090 & 0.110\end{array}$ Optical depth

Figure 3 | Contrail-cirrus radiative forcing and optical depth at $250 \mathrm{hPa}$ for the year 2002. Net radiative forcing (without correcting for long-wave scattering) (a) and solar optical depth (b) of contrail cirrus.

than $300 \mathrm{~mW} \mathrm{~m}^{-2}$ over the eastern US and central Europe. Over most of the US, Europe, over the North Atlantic flight corridor and also over parts of southeast Asia, net radiative forcing exceeds $100 \mathrm{~mW} \mathrm{~m}^{-2}$. Over much of the northern mid-latitudes contrailcirrus radiative forcing exceeds $30 \mathrm{~mW} \mathrm{~m}^{-2}$. Maxima in radiative forcing are found in areas of maxima in contrail-cirrus coverage, but radiative forcing is enhanced in areas with large contrail-cirrus optical depth (Fig. 3b). This means that for a fixed contrail-cirrus coverage, radiative forcing is larger over southeast Asia than in the northern mid-latitudes and slightly larger over the eastern US than over central Europe or the North Atlantic flight corridor.

Globally the long-wave radiative forcing due to young contrails amounts to $5.5 \mathrm{~mW} \mathrm{~m}^{-2}$. This estimate is in line with an earlier estimate of line-shaped-contrail long-wave radiative forcing using the same model but an independent technique ${ }^{22}$. The latter estimate is slightly lower because the randomly overlapped visible lineshaped-contrail coverage in the earlier study $(0.06 \%)$ is slightly smaller than our visible young-contrail coverage using the same overlap assumption $(0.07 \%)$. Short-wave radiative forcing due to young contrails amounts globally to $-1.2 \mathrm{~mW} \mathrm{~m}^{-2}$. This value is about $50 \%$ larger than the value we obtain when neglecting the diurnal cycle of air traffic, resulting from the fact that most flights are daytime flights ${ }^{31,32}$. Net radiative forcing due to young contrails amounts globally to $4.3 \mathrm{~mW} \mathrm{~m}^{-2}$, which is at the lower bound of the range of radiative-forcing estimates for line-shaped contrails ${ }^{3,31}$. This may imply that our contrail-cirrus radiative forcing constitutes a low estimate as well. Differences between our short-wave and long-wave forcing estimates and those in the literature are likely to be due to differences in: (1) the spatial and temporal distribution of contrail coverage and its optical depth resulting from the differences in the parameterization schemes; (2) the background cloud fields and

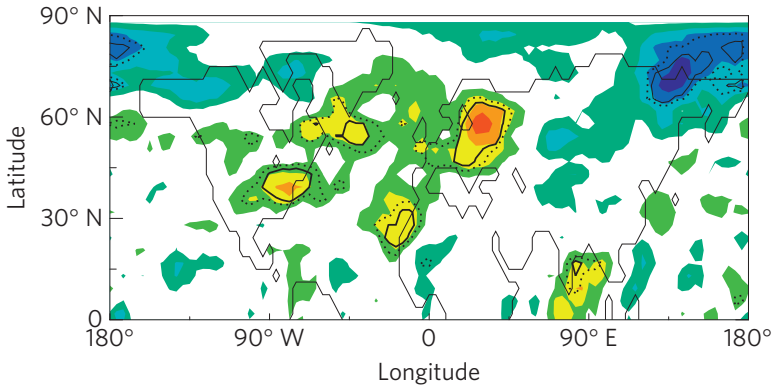

b
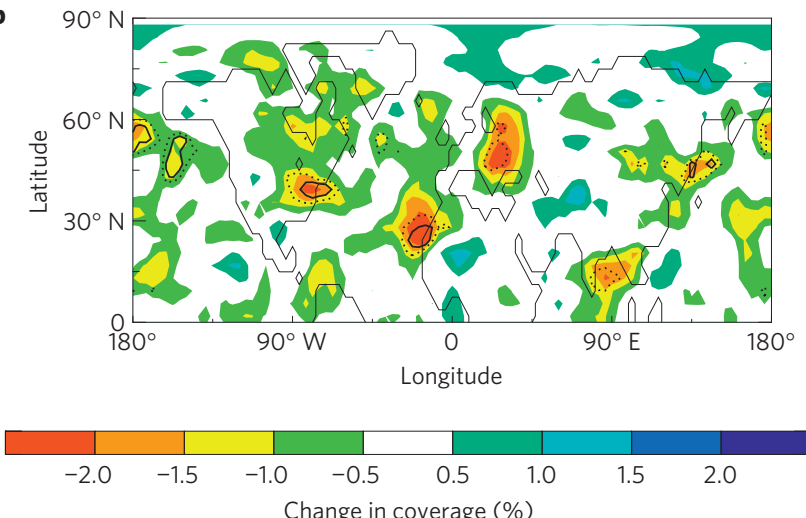

Figure 4 | Change in natural-cirrus coverage due to the presence of contrail cirrus. Change in natural-cirrus coverage at the main flight level of $230 \mathrm{hPa}$ (a) and when overlapping all ice clouds within one vertical column (b). Dotted lines indicate the $90 \%$ confidence interval and solid lines the $95 \%$ confidence interval.

their overlap with the contrails; (3) the flight inventories and their reference years used.

The global net radiative forcing of contrail cirrus is roughly nine times that of young contrails, making it the single largest radiativeforcing component connected with aviation. It is important to note that contrail cirrus have a much shorter lifetime than long-lived greenhouse gases. This difference in lifetime influences the relative importance of contrail cirrus and other forcing agents for climate change when estimating their impact for remote time horizons ${ }^{33}$.

The uncertainty in the spreading rate effective in ECHAM4CCMod (ref. 25) introduces an uncertainty in the estimate of contrail-cirrus net radiative forcing of $\pm 5 \mathrm{~mW} \mathrm{~m}^{-2}$. The sensitivity of contrail-cirrus radiative forcing to optical depth and ice-particle shape of contrail cirrus, to the flight inventory and to the model's radiation code is likely to be similar to that of line-shaped contrails. Therefore, we estimate that the uncertainty related to the first two variables amounts in ECHAM4 to an uncertainty in contrail-cirrus radiative forcing of $\sim 25 \%$ (ref. 34 ) and $\sim 15 \%$ (ref. 35), respectively. The sensitivity of global radiative forcing to the flight inventory is probably small ${ }^{35}$. Furthermore, it has been shown that the radiative response due to contrails varies by $\pm 22 \%$ around a multi-model mean $^{36}$. An estimate of the combined uncertainty of radiative forcing would need to take into account the interdependence between the different uncertainties.

\section{Reduction of natural cirrus coverage and optical depth}

Contrail cirrus change the water budget of the surrounding atmosphere and therefore can have an impact on natural clouds. Water vapour that is deposited on ice particles within contrail cirrus is not available for formation and deposition in natural cirrus any longer. Therefore, contrail cirrus have the potential to modulate the optical properties of natural clouds, delaying their onset and replacing them, which may partly offset the direct climate impact 
of contrail cirrus. Virtually nothing is known about those cloud and humidity changes.

We have carried out long-term integrations using ECHAM4CCMod with and without prescribing air traffic. At the main flight level at $230 \mathrm{hPa}$, where we would expect a maximum impact of contrail cirrus on the natural-cloud coverage due to the maximum in contrail-cirrus coverage, the two simulations exhibit differences in natural-cirrus coverage in the main traffic areas (Fig. 4a). Reductions in the natural-cirrus coverage of around $2 \%$ can be found over northeastern Europe and over the east coast of the US. Over the western part of the main transatlantic air-traffic route, off the west coast of northwest Africa and west of the main contrail-cirrus area of southeast Asia, reductions range between 1 and $1.5 \%$. These changes are different from zero at the $95 \%$ significance level (when taking into account serial correlations), whereas the local decrease over southeast Asia is mostly significant only at the $90 \%$ level. Furthermore, a statistically significant increase in cirrus coverage can be found over and north of eastern Siberia. In those areas, the $230 \mathrm{hPa}$ level lies frequently within the stratosphere. Owing to a cold and moist bias in the polar lower stratosphere, common to many climate models ${ }^{37}$, the model has a higher sensitivity to the moisture input than would be expected in nature. Therefore, we will not discuss this signal any further. Maxima of decrease in natural-cirrus coverage lie consistently downstream of the maxima in contrail-cirrus coverage (compare with Fig. 1a). The change in cirrus coverage, calculated by vertically overlapping all ice clouds in a column (Fig. 4b), confirms that the natural-cirrus coverage is decreased owing to the presence of contrail cirrus. The decrease is slightly less significant owing to the large natural variability in cloud coverage. We note that over the North Pacific flight corridor natural-cirrus coverage is also significantly changed and that the increase in cirrus coverage over Siberia at $230 \mathrm{hPa}$ does not translate into an increase in overlapped cirrus coverage in the area.

Locally, the decrease in natural-cirrus coverage (over Europe and the US) amounts to up to $10 \%$ of the natural-cirrus coverage or up to $20 \%$ of the contrail-cirrus coverage. Furthermore, in the main contrail-cirrus areas of North America and Europe, the optical depth of natural clouds is significantly (at the 95\% significance level) reduced by up to $10 \%$ owing to the presence of contrail cirrus.

Both changes in natural-cirrus coverage and optical depth exert a negative net radiative forcing (cooling), partly offsetting the positive net radiative forcing due to contrail cirrus. The large natural variability in albedo, sea surface temperature, natural clouds and so on, all of which influence the radiative fluxes in the atmosphere, impedes the isolation of the relatively small change in natural-cirrus radiative forcing. Assuming that the decrease in natural-cirrus coverage amounts to approximately one fifth of the global contrail-cirrus coverage (as we have found a maximum of $2 \%(1.5 \%)$ decrease of natural-cirrus coverage downstream of the areas of $10 \%(6 \%)$ contrail-cirrus coverage over Europe (US)), the feedback due to this change in natural-cirrus cloudiness would induce a cooling of approximately a fifth of contrail-cirrus radiative forcing, that is $-7 \mathrm{~mW} \mathrm{~m}^{-2}$. This estimate is very uncertain and further work is needed to more reliably quantify the feedback.

\section{Implications for evaluating the impact of aviation}

We report a model-based estimate of the global climate impact of contrail cirrus, comprising not only young or line-shaped but also aged, irregularly shaped contrails, and including resulting changes in cirrus cloudiness. Defining the radiative forcing due to contrail-induced cloudiness (CIC) as the contrail-cirrus radiative forcing offset by the natural-cloud feedback results in a radiative forcing by CIC of about $31 \mathrm{~mW} \mathrm{~m}^{-2}$. Net radiative forcing due to $\mathrm{CIC}$ constitutes one of the largest single aviation-related radiativeforcing components. This radiative forcing due to CIC together with the timescale on which the climate impact is to be evaluated or reduced needs to be considered ${ }^{33}$ in aviation climate-impact assessments or mitigation studies, respectively.

Besides the uncertainty due to the treatment of contrail cirrus, our radiative-forcing estimates are also affected particularly by uncertainties related to the model's representation of uppertropospheric humidity and clouds. Clouds are influenced by small-scale processes that cannot be resolved by a large-scale climate model and which therefore need to be parametrized. The representation of clouds is a major source of uncertainty in climate simulations ${ }^{4}$. The same problems also affect the representation of contrail cirrus.

The uncertainty of the radiative-forcing estimates should be evaluated from independent studies based on different models and contrail-cirrus parameterizations. Reducing the uncertainty in the evaluation of contrail-cirrus radiative forcing requires more and better observational data sets ${ }^{24,38}$. In the long term, progress in this research area requires advanced representation of natural clouds and humidity in climate models and appropriate data sets for their validation ${ }^{39,40}$.

\section{Methods}

The contrail-cirrus module, CCMod, introduces a new cloud class 'contrail cirrus' in the global climate model ECHAM4. It is based on a prognostic treatment of fractional coverage, length and ice water mixing ratio of contrail cirrus ${ }^{25}$ The processes controlling contrail-cirrus coverage and properties, which are contrail formation below a threshold temperature ${ }^{14}$, advection, spreading and water deposition, sublimation and precipitation, are parametrized physically consistent with the parametrization of natural clouds ${ }^{25}$. Of the flight distance, only a fraction (given by the supersaturated area fraction) results in persistent contrails. CCMod simulates the life cycle of those persistent contrails. Contrails are advected by the wind field and remain in (and are limited by) the ice-supersaturated fraction of a grid box, assuming that persistent contrail cirrus predominantly form in large persistent ice-supersaturated areas, such as prefrontal areas, in which they remain for a long time. Supersaturated areas are inferred from the assumptions of subgrid-scale variability given by the cloud scheme ${ }^{17}$. Contrail cirrus spread proportional to the vertical wind shear and their vertical extent. In nature, the vertical extent is dependent on ice-particle sedimentation and is limited by the thickness of a supersaturated layer. After $1 \mathrm{~h}$, the contrail's vertical extent is set in CCMod to the model's layer depth, approximately $700 \mathrm{~m}$, which is roughly in line with observations ${ }^{41}$. Contrails dissipate as their ice water content is reduced by sublimation and precipitation. Within the contrail-cirrus cloud class, fractional coverage and length of young contrails (up to $5 \mathrm{~h}$ old) are tracked independently, allowing the analysis of the coverage due to young contrails for purely validational purposes. The ice water content due to young contrails has not been tracked independently, prohibiting the analysis of the optical depth of young contrails.

The ECHAM4 diagnostic cloud-coverage scheme is relative-humidity based and the cloud water content is prognostic ${ }^{26}$. Cloud particle fall speeds are dependent on the cloud water content. The model's water budget was changed to accommodate for the new cloud class ${ }^{25}$, enabling the simulation of the competition for available water vapour between natural and contrail cirrus. Water vapour deposition, sublimation, precipitation and optical depth of natural cirrus and contrail cirrus are dependent on their respective ice water content. CCMod has been evaluated using satellite and in situ measurements of ice supersaturation (ref. 17 and N. Lamquin et al., manuscript in preparation) and regional observations of line-shaped-contrail coverage ${ }^{25}$. As only observational data sets of line-shaped contrails and none of contrail cirrus are available, coverage and optical properties of contrail cirrus could not be validated.

Stratosphere-adjusted radiative forcing has been calculated as a difference between different calls of the radiation scheme at each time step in a model $\operatorname{run}^{42}$, allowing the online calculation of radiative forcing due to contrail cirrus For the radiation calculations, natural clouds and contrail cirrus have been randomly overlapped in the vertical at each model time step, except when clouds existed in neighbouring model levels, in which case clouds were stacked above each other (maximum random overlap). This allows natural clouds and contrail cirrus to overlap each other in the vertical. The coverage due to contrail cirrus shown in Fig. 1 was calculated by assuming maximum random overlap among contrail cirrus alone. Only part of this coverage leads to an increase in overall cloud coverage.

Simulations have been conducted using an hourly resolved version of the global air traffic inventory AERO2k (ref. 43) for the year 2002. Integrations of 10 and $35 \mathrm{yr}$ with the ECHAM4-CCMod climate model (using a time step of $30 \mathrm{~min}$, a horizontal resolution of T30 and 39 vertical levels) have been carried out to estimate contrail-cirrus coverage and radiative forcing and the feedback of contrail cirrus on natural clouds. 
Received 13 December 2010; accepted 1 March 2011; published online 29 March 2011

\section{References}

1. Boucher, O. Air traffic may increase cirrus cloudiness. Nature 397, 30-31 (1999).

2. Stordal, F. et al. Is there a trend in cirrus cloud cover due to aircraft traffic? Atmos. Chem. Phys. 5, 2155-2162 (2005).

3. Lee, D. S. et al. Aviation and global climate change in the 21st century. Atmos. Environ. 43, 3520-3537 (2009).

4. IPCC Climate Change 2007: The Physical Science Basis (eds Solomon, S. et al.) (Cambridge Univ. Press, 2007).

5. Schumann, U. \& Wendling, P. in Air Traffic and the Environment-Background, Tendencies and Potential Global Atmospheric Effects (ed. Schumann, U.) 138-153 (Lecture Notes in Engineering, Springer, 1990).

6. Minnis, P. et al. Transformation of contrails into cirrus during SUCCESS Geophys. Res. Lett. 25, 1157-1160 (1998).

7. Haywood, J. M. et al. A case study of the radiative forcing of persistent contrails evolving into contrail-induced cirrus. J. Geophys. Res. 114, D24201 (2009).

8. Kärcher, B., Möhler, O., DeMott, P. J., Pechtl, S. \& Yu, F. Insights into the role of soot aerosols in cirrus cloud formation. Atmos. Chem. Phys. 7, 4203-4227 (2007).

9. Hendricks, J., Kärcher, B., Lohmann, U. \& Ponater, M. Do aircraft black carbon emissions affect cirrus clouds on the global scale? Geophys. Res. Lett. 32 , L12814 (2005).

10. Liu, X., Penner, J. E. \& Wang, M. Influence of anthropogenic sulphate and black carbon on upper tropospheric clouds in the NCAR CAM3 coupled to the IMPACT global aerosol model. J. Geophys. Res. 114, D03204 (2009).

11. Minnis, P. in Encyclopedia of Atmospheric Sciences (eds Holton, J., Pyle, J. \& Curry, J.) 509-520 (Academic, 2003)

12. Meerkötter, R. et al. Radiative forcing by contrails. Ann. Geophys. 17, 1080-1094 (1999).

13. Appleman, H. The formation of exhaust contrails by jet aircraft. Bull. Am. Meteorol. Soc. 34, 14-20 (1953).

14. Schumann, U. Influence of propulsion efficiency on contrail formation. Aerosp. Sci. Technol. 4, 391-401 (2000).

15. Koop, T., Luo, B. P., Tsias, A. \& Peter, T. Water activity as the determinant for homogeneous ice nucleation in aqueous solutions. Nature 406, 611-614 (2000).

16. Sausen, R., Gierens, K., Ponater, M. \& Schumann, U. A diagnostic study of the global distribution of contrails. Theor. Appl. Clim. 61, 127-141 (1998).

17. Burkhardt, U., Kärcher, B., Ponater, M., Gierens, K. \& Gettelman, A. Contrail cirrus supporting areas. Geophys. Res. Lett. 35, L16808 (2008).

18. Seinfeld, J. H. Clouds, contrails and climate. Nature 391, 837-838 (1998).

19. Bakan, S., Betancor, M., Gayler, V. \& Graßl, H. Contrail frequency over Europe from NOAA satellite images. Ann. Geophys. 12, 962-968 (1994).

20. Meyer, R., Mannstein, H., Meerkötter, R., Schumann, U. \& Wendling, P. Regional radiative forcing by line-shaped contrails derived from satellite data. J. Geophys. Res. 107, 4104 (2002).

21. Palikonda, R., Minnis, P., Duda, D. P. \& Mannstein, H. Contrail coverage derived from 2001 AVHRR data over the continental United States of America and surrounding areas. Meteorol. Z. 14, 525-536 (2005).

22. Marquart, S., Ponater, M., Mager, F. \& Sausen, R. Future development of contrail cover, optical depth, and radiative forcing: Impacts of increasing air traffic and climate change. J. Clim. 16, 2890-2904 (2003).

23. Ponater, M., Marquart, S. \& Sausen, R. Contrails in a comprehensive global climate model: Parameterization and radiative forcing results. J. Geophys. Res. 107, 4164 (2002)

24. Burkhardt, U., Kärcher, B. \& Schumann, U. Global modelling of the contrail and contrail cirrus climate impact. Bull. Am. Meteorol. Soc. 91, 479-483 (2010).
25. Burkhardt, U. \& Kärcher, B. Process-based simulation of contrail cirrus in a global climate model. J. Geophys. Res. 114, D16201 (2009).

26. Roeckner, E. et al. Max-Planck-Inst. Meteorol. Rep. 218, 90 (Hamburg, 1996).

27. Sassen, K. \& Cho, B. S. Subvisual-thin cirrus lidar dataset for satellite verification and climatological research. J. Appl. Meteorol. 31, $1275-1285$ (1992).

28. Kärcher, B., Burkhardt, U., Unterstrasser, S. \& Minnis, P. Factors controlling contrail cirrus optical depth. Atmos. Chem. Phys. 9, 6229-6254 (2009).

29. McFarquhar, G. M., Heymsfield, A. J., Spinhirne, J. \& Hart, B. Thin and subvisual tropopause tropical cirrus: Observations and radiative impacts. J. Atmos. Sci. 57, 1841-1853 (2000).

30. Marquart, S. \& Mayer, B. Towards a reliable GCM estimation of contrail radiative forcing. Geophys. Res. Lett. 29, 1179 (2002).

31. Stuber, N. \& Forster, P. The impact of diurnal variations of air traffic on contrail radiative forcing. Atmos. Chem. Phys. 7, 3153-3162 (2007).

32. Stuber, N., Forster, P., Rädel, G. \& Shine, K. The importance of the diurnal and annual cycle of air traffic for contrail radiative forcing. Nature 441, 864-867 (2006).

33. Fuglestvedt, J. S. et al. Transport impacts on atmosphere and climate: Metrics. Atmos. Environ. 44, 4648-4677 (2010).

34. Kärcher, B., Burkhardt, U., Ponater, M. \& Frömming, C. Importance of representing optical depth variability for estimates of global line-shaped contrail radiative forcing. Proc. Natl Acad. Sci. USA 107, 19181-19184 (2010).

35. Frömming, C. et al. Sensitivity of contrail coverage and contrail radiative forcing to selected key parameters. Atmos. Environ. 45, 1483-1490 (2011).

36. Myhre, G. et al. Intercomparison of radiative forcing calculations of stratospheric water vapour and contrails. Meteorol. Z. 18, 585-596 (2009).

37. Boer, G. et al. Some results from an intercomparison of the climate simulated by 14 general circulation models. J. Geophys. Res. 97, 12771-12786 (1992).

38. Heymsfield, A. et al. Contrail microphysics. Bull. Am. Meteorol. Soc. 91, $465-472$ (2010)

39. Zhang, M. H. et al. Comparing clouds and their seasonal variations in 10 atmospheric general circulation models with satellite measurements. J. Geophys. Res. 110, D15S02 (2005).

40. Waliser, D. E. et al. Cloud ice: A climate model challenge with signs and expectations of progress. J. Geophys. Res. 114, D00A21 (2009).

41. Freudenthaler, V., Homburg, F. \& Jäger, H. Contrail observations by ground-based scanning Lidar: Cross-sectional growth. Geophys. Res. Lett. 22, 3501-3504 (1995).

42. Stuber, N., Sausen, R. \& Ponater, M. Stratosphere adjusted radiative forcing calculations in a comprehensive climate model. Theor. Appl. Climatol. 68, 125-135 (2001).

43. Eyers, C. J. et al. AERO2K Global Aviation Emissions Inventories for 2002 and 2025: Technical Report QINETIC/04/01113 (QinetiQ, 2004).

\section{Acknowledgements}

We thank M. Ponater for providing us with a code for calculating stratosphere-adjusted radiative forcing and for comments and U. Schumann for the diurnal cycle of air traffic. This work was carried out within the DLR project 'Climate compatible air transport system'.

\section{Author contributions}

The concepts of the parametrization were jointly developed and discussed by U.B. and B.K. U.B. carried out the research and wrote the paper.

\section{Additional information}

The authors declare no competing financial interests. Reprints and permissions information is available online at http://npg.nature.com/reprintsandpermissions. Correspondence and requests for materials should be addressed to U.B. 